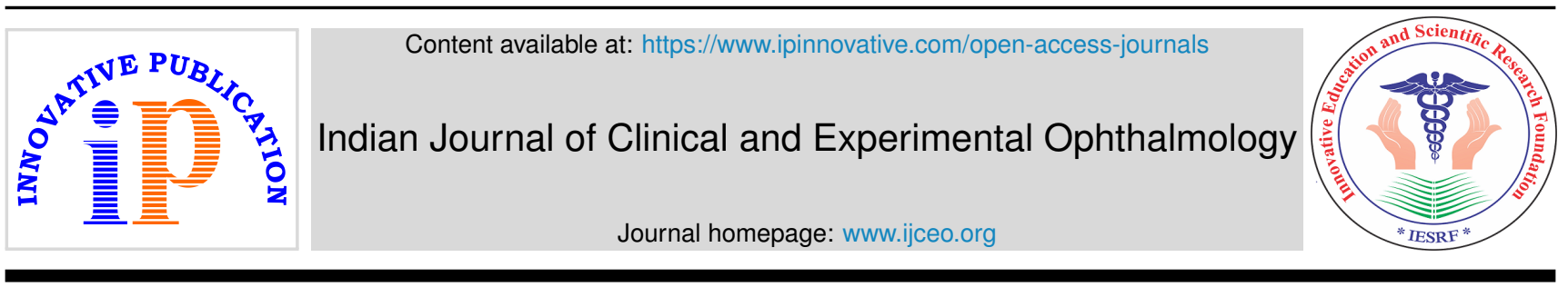

\title{
Editorial
}

\section{Post COVID-19 Mucormycosis: What is role of iron and iron chelating agents?}

\author{
Rajendra P Maurya ${ }^{1}$,* \\ ${ }^{1}$ Regional Institute of Ophthalmology, Institute of Medical Sciences, Banaras Hindu University, Varanasi, Uttar Pradesh, India
}

\section{A R T I C L E I N F O}

Article history:

Received 08-06-2021

Accepted 12-06-2021

Available online 30-06-2021

\begin{abstract}
(c) This is an open access article distributed under the terms of the Creative Commons Attribution License (https://creativecommons.org/licenses/by/4.0/) which permits unrestricted use, distribution, and reproduction in any medium, provided the original author and source are credited.
\end{abstract}

Mucormycosis is a rapidly progressive, life threatening, angio-invasive opportunistic fungal infection caused by fungi of the order Mucorales like Rhizopus and Mucor. Rhino-orbito-cerebral mucormycosis (ROCM) is the most devastating complication of Coronavirus disease 2019 (COVID-19). India has seen a sudden rise in cases of ROCM over the past few months due to the increasing frequency of risk factors like corticosteroid therapy, uncontrolled diabetes, diabetic ketoacidosis, neutropenia and iron overload etc. ${ }^{1}$

Increased level of available serum iron is most important risk factor to infection by Mucorales. Iron is essential for growth and virulence of fungi of the class Zygomycetes. ${ }^{1,2}$ It has been reported that Rhizopus Oryzae, most common fungi causing mucormycosis, grows poorly in iron deprived serum. ${ }^{3}$ Iron carrier proteins like transferrin and ferritin plays role of major host defense mechanism against infection by Rhizopus. ${ }^{1,3}$ In diabetic patients, ketoacidosis (low blood $\mathrm{pH}$ ) and excessive glycosylation of carrier proteins results in decreased affinity of transferrin to bind iron and thus disrupts host defense mechanism. ${ }^{3,4}$ Patients of DKA have elevated levels of available serum iron due to release of iron from transferrin-iron complex. ${ }^{5}$

The genome sequencing project of Rhizopus Oryzae demonstrated several genes which are involved in iron uptake system such as high affinity iron permease gene (FTR1), rhizoferrin (siderophore synthesis) and genes for

\footnotetext{
* Corresponding author.

E-mail address: mauryarp_bhu@yahoo.com (R. P. Maurya).
}

iron uptake from haem. Gene encoding high-affinity iron permease was over expressed by Mucorales. The reduction of FTR1 or inactivation of FTR1 by anti-FTR1 antibody reduces the virulence of mucormycosis. ${ }^{3}$

Animal model demonstrated that, deferoxamine is a bacterial siderophore, which acts as an iron chelator with respect to the host and it is utilized by Rhizopus for extracting iron. ${ }^{6}$ Deferoxamine has high affinity for iron and can extract iron from transferrin. Rhizopus binds to iron-deferoxamine complex through specific receptors and liberate the iron via energy dependent reductase process. ${ }^{7,8}$ Boelaert et al. reported that deferoxamine, an iron chelator augments growth and pathogenicity of invasive mucormycosis while other hydroxypyridine chelators have no effect. ${ }^{6}$

Deferiprone is a $\alpha$-ketohydroxypyridine group iron chelators approved in India and Europe for treatment of patients with iron overload. ${ }^{9}$ Deferasirox is also an iron chelator recently approved by US FDA for treatment of transfusion related iron overload, ${ }^{10}$ has been used as salvage therapy for rhino-cerebral mucormycosis. ${ }^{2,11}$ Unlike deferoxamine, Rhizopus can not utilize deferiprone / deferasirox as xenosiderophores for iron extraction. ${ }^{6}$ Thus iron-chelators like deferiprone or deferasirox can be used as adjuvant/salvage therapy for mucormycosis. Role of combination therapy including iron chelators and anti-fungal are under investigation. ${ }^{12}$ Though recently completed phase-II, double blind, randomized, placebocontrolled trial of liposomal amphotericin-B and deferasirox 
(20mg/kg/day for 2 weeks) showed no much benefit. ${ }^{13}$ Iron chelation is a novel therapeutic strategy for mucormycosis, further investigations are warranted to evaluate the role of combination of anti-fungal and iron chelation therapy.

\section{References}

1. Spellberg B, Edwards J, Ibrahim A. Novel Perspectives on Mucormycosis: Pathophysiology, Presentation, and Management. Clin Microbiol Rev. 2005;18(3):556-9. 101:10.128/cmr.183.556 5692005 .

2. Ibrahim AS, Edwards JE, Fu Y, Spellberg B. Deferiprone iron chelation as a novel therapy for experimental mucormycosis. $J$ Antimicrob Chemother. 2006;58(5):1070-3. [0i:10.1093//ac/dk1350.

3. Artis WM, Fountain JA, Delcher HK, Jones HE. A mechanism of susceptibility to mucormycosis in diabetic ketoacidosis: transferring and iron availability. Diabetes. 1982;31(12):1109-14.

4. Ribes JA, Vanover-Sams CL, Baker DJ. Zygomycetes in Human Disease. Clin Microbiol Rev. 2000;13(2):236-301.

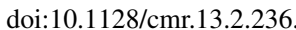

5. Ibrahim AS, Spellberg B, Walsh TJ, Kontoyiannis DP. Pathogenesis of Mucormycosis. Clin Infect Dis. 2012;54(suppl_1):S16-S22.

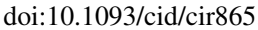

6. Boelaert JR, Cutsem JV, de Locht M, Schneider YJ, Crichton RR. Deferoxamine augments growth and pathogenicity of Rhizopus, while hydroxypyridinone chelators have no effect. Kidney Int. 1994;45(3):667-71. 10i:101038/ki. 1994.89

7. Boelaert JR, de Locht M, Cutsem JV, Kerrels V, Cantinieaux B, Verdonck A, et al. Mucormycosis during deferoxamine therapy is a siderophore-mediated infection. In vitro and in vivo animal studies. $J$ Clin Invest. 1993;91(5):1979-86. ब01:10.11/2/jc116419.

8. Locht MD, Boelaert JR, Schneider YJ. Iron uptake from ferrioxamine and from ferrirhizoferrin by germinating spores of rhizopus microsporus. Biochem Pharmacol. 1994;47(10):1843-50. doi:10.1016/0006-2952(94)90314-x.
9. Hoffbrand AV, Cohen A, Hershko C. Role of deferiprone in chelation therapy for transfusional iron overload. Blood. 2003;102(1):17-24. 10i:10. 182/blood-2002-06-1867.

10. Cappellini M. Iron-chelating therapy with the new oral agent ICL670 (Exjade ${ }^{\circledR}$ ). Best Pract Res Clin Haematol. 2005;18(2):289-98. dol:10.1016/..beha.2004.09.002

11. Reed C, Ibrahim A, Edwards JE, Walot I, Spellberg B. Deferasirox, an Iron-Chelating Agent, as Salvage Therapy for Rhinocerebra Mucormycosis. Antimicrob Agents Chemother. 2006;50(11):3968-9. do:-10س28/aac.01065-06.

12. Donnelly JP, Lahav M. Deferasirox as adjunctive therapy for mucormycosis. J Antimicrob Chemother. 2012;67(3):519-20. 001:10.1093/jac/dkr540.

13. Spellberg B, Ibrahim AS, Chin-Hong PV, Kontoyiannis DP, Morris MI, Perfect JR, et al. The Deferasirox-AmBisome Therapy for Mucormycosis (DEFEAT Mucor) study: a randomized, doubleblinded, placebo-controlled trial. $J$ Antimicrob Chemother. 2012;67(3):715-22. doi:10.1093/jac/dkr375.

\section{Author biography}

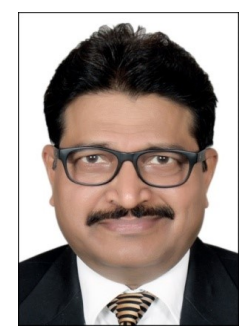

Rajendra P Maurya, Editor in Chief IJCEO, Associate Professor \& I/c Orbit, Ocular Oncology and Oculoplasty Unit Regional Institute of Ophthalmology, Institute of Medical Sciences, Banaras Hindu University, Varanasi, (UP), India E-mail: editorijceo@gmail.com, mauryarp_bhu@yahoo.com

Cite this article: Maurya RP. Post COVID-19 Mucormycosis: What is role of iron and iron chelating agents?. Indian J Clin Exp Ophthalmol 2021;7(2):253-254. 